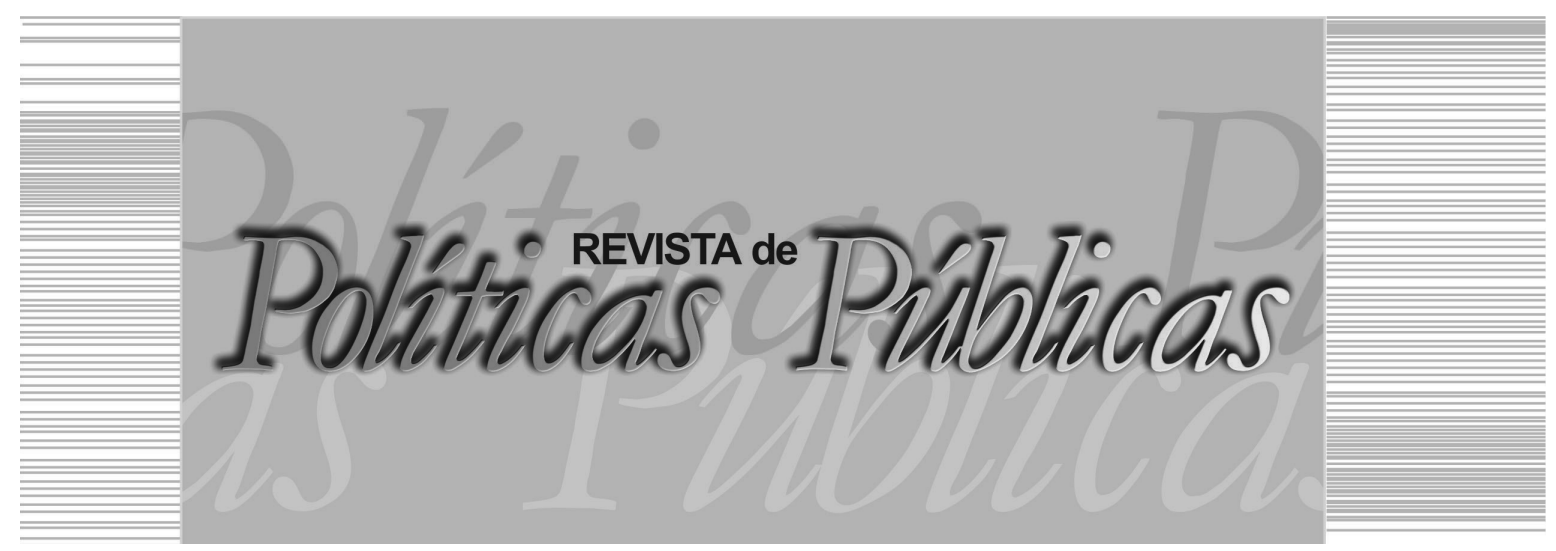

\title{
GOVERNO DOS ALGORITMOS
}

\author{
Sergio Amadeu Silveira ${ }^{1}$ \\ Universidade Federal do ABC (UFABC)
}

\section{Resumo}

Este texto trata da governamentalidade dos algoritmos no setor público. Debate as noções de governo, governança e governamentalidade. A partir dessas definições mostra o nível de penetração dos algoritmos em nossa sociedade e indica a tendência de expansão de seu uso nas instituições do Estado. Por fim, analisa as implicações dos algoritmos no setor público e os desafios de mantê-los sob controle de uma gestão democrática e socialmente inclusiva, superando as perspectivas tecnocráticas, positivistas e neoliberais.

Palavras-chave: Algoritmo, governamentalidade algorítmica, regulação algorítmica, performatividade, tecnopolítica.

\section{GOVERNMENT OF ALGORITHMS}

\begin{abstract}
This paper discusses the governmentality of algorithms in the public sector. It debates the notions of government, governance and governmentality. From these definitions show the level of penetration of algorithms in our society and indicates the trend of expansion of its use in state institutions. Finally, it analyzes the implications of algorithms in the public sector and the challenges of keeping them under the control of a democratic and socially inclusive management, surpassing the technocratic, positivist and neoliberal perspectives. Key words: Algorithm, algorithmic governamentality, algorithmic regulation, performativity, technopolitics.
\end{abstract}

\footnotetext{
Cientista Social, Doutor em Ciência Política pela Universidade de São Paulo (USP), Professor da Universidade Federal do ABC (UFABC). E-mail: sergio.amadeu@ufabc. edu.br / Universidade Federal do ABC - UFABC: Av. dos Estados, 5001 - Bairro Santa Terezinha - Santo André. CEP: 09210-580
} 


\section{INTRODUÇÃO}

Algoritmos podem ser definidos como rotinas logicamente encadeadas. Também podem ser compreendidos como o conjunto de instruções introduzidas em uma máquina para resolver um problema bem definido. (INTRONA, 2013). "Algoritmos fazem coisas, e sua sintaxe incorpora uma estrutura de comando para permitir que isso aconteça." (GOFFEY, 2008, p. 17). Em geral, eles expressam uma solução computacional em termos de suas condições lógicas (conhecimento sobre o problema) a partir de estruturas de controle, ou seja, estratégias para resolver o problema. (KOWALSKI, 1979).

Expressões como sociedade da informação (MACHLUP, 1962) ou sociedade em rede (CASTELLS, 1999) compõem cenários caracterizados pelo uso intensivo de softwares (MANOVICH, 2013) o que implica a ampla disseminação de algoritmos. Celulares, tablets, smart TVs, veículos, semáforos inteligentes, mecanismos de busca na web, sistemas de aprovação de crédito bancário, entre tantos outros exemplos corriqueiros, todos esses dispositivos indicam a crescente presença dos algoritmos em nosso convívio. A paisagem sociotécnica está repleta de algoritmos, graças a seu enorme sucesso e eficácia em nossas relações sociais, econômicas e políticas. Mesmo assim, softwares e algoritmos são invisíveis para a maioria das pessoas. Esses códigos são apresentados pelo mercado como algo que não precisamos saber como existem ou como funcionam, desde que cumpram suas finalidades.

O sociólogo Philip N. Howard (2015), em uma brilhante comparação com o Império Romano, chamou de Pax Técnica o arranjo político, econômico e cultural de instituições e dispositivos em rede nos quais governo e indústria estão firmemente ligados em pactos de defesa mútua, colaborando com projetos, com design, com a definição de padrões, com a mineração e análise de dados. Esse arranjo, pouco democrático e voltado prioritariamente ao fortalecimento das corporações, tende a se ampliar caso não seja tornado visível, caso os algoritmos não sejam analisados criticamente diante do avanço de tecnologias como Big Data, Internet das Coisas, Machine Learning e Inteligência Artificial, entre outras. 


\section{GOVERNO, GOVERNANCA E GOVERNAMENTALIDADE}

Quando se pensa na palavra governo, as correntes principais da Ciência Política tratam da instituição ou da ação em torno do Estado moderno. O sociólogo Max Weber definiu o Estado como uma "[...] relação de dominação do homem sobre o homem, fundada no instrumento da violência legítima (isto é, da violência considerada como legítima)." (WEBER, 2004, p. 57). Governar, nessa concepção, significa dirigir a política de Estado e expressa relações de poder, legitimidade e dominação.

Lucio Levi (1986) nos alertou para a diferença que a palavra government adquire nos países anglo-saxônicos aquilo que no continente europeu se designa com a expressão regime político. O que se designa na Itália com a palavra Governo, "[...] na língua inglesa se usam outros termos como cabinet na Grã-Bretanha e administration nos Estados Unidos." (LEVI, 1986, p. 553). Já os regimes políticos dizem respeito ao conjunto de instituições que regulam a luta pelo poder e seu exercício. Uma das mais conhecidas tipologias dos regimes políticos foi herdada de Aristóteles: governo de um, governo de poucos e governo de muitos.

Este texto utilizará outra perspectiva para o termo governo, que será baseada nos estudos de Michel Foucault. No curso dado no Collège de France, em 1978, intitulado Segurança, Território e População, Foucault (2008b) registrou um conjunto de reflexões sobre as questões do governo e da governamentalidade a partir de sua análise da política moderna dos séculos XVII e XVIII.

Por governamentalidade, eu entendo o conjunto constituído pelas instituições, procedimentos, análises e reflexões, cálculos e táticas que permitem exercer essa forma bastante específica e complexa de poder que tem por alvo a população, como forma principal de saber a economia política e por instrumentos técnicos essenciais os dispositivos de segurança. Em segundo lugar, por "governamentalidade" entendo a tendência, a linha de força que, em todo o Ocidente, não parou de conduzir, e desde há muito, para a preeminência desse tipo de poder que podemos chamar de "governo" sobre todos os outros - soberania, disciplina -- e que trouxe, por um lado, o desenvolvimento de toda uma série de aparelhos específicos de governo [e, por outro lado], o desenvolvimento de toda uma série de saberes. Enfim, por "governamentalidade", creio que se deveria entender o processo, ou antes, o resultado do processo pelo qual o Estado de justiça da Idade Média, que nos séculos XV e XVI se 
tornou Estado administrativo, viu-se pouco a pouco "governamentalizado". (FOUCAULT, 2008b, p. 143-144, grifos do autor).

Governar é conduzir condutas, segundo o pensador francês. Foucault considera que o poder não expressa apenas confronto, o poder constitui também vínculos, inclusive aqueles que implicam o governo. Para Foucault (2008b), existem formas de governo de si e de governo dos outros. O significado do termo governo é bem mais amplo do que o circunscrito pela sua definição de soberania e pelas formulações jurídicas. Assim, governo tem uma significação bastante ampla como a existente no século XVI: "[...] [o governo] não se referia apenas às estruturas políticas e à gestão dos Estados, mas designava a maneira de dirigir a conduta dos indivíduos ou dos grupos: governo das crianças, das almas, das comunidades, das famílias, dos doentes." (FOUCAULT, 1995, p.244).

A ideia de que o ato governar "[...] é estruturar o eventual campo de ação dos outros." (FOUCAULT, 1995, p. 244) se torna fundamental para analisarmos como gestores e cidadãos podem pensar o poder em relação aos dispositivos - os algoritmos - que são criados por empresas que, em muitos casos, buscam objetivos bem distantes daqueles declarados pelas leis e pelos programas e projetos formulados no interior do Estado. Pensadores liberais e neoliberais buscaram explorar outro termo menos comprometido com o Estado e mais compromissado com a concorrência no mercado, ou seja, o termo governança.

James N. Rosenau (2000), cientista político norte-americano, propunha uma definição de governança bem distinta da noção de governo. Esses termos em Rosenau (2000, p. 15-16) têm significado diferente dos utilizados por Foucault, como podemos notar a seguir:

[...] governo sugere atividades sustentadas por uma autoridade formal, pelo poder de polícia que garante a implementação das políticas devidamente instituídas, enquanto governança refere-se a atividades apoiadas em objetivos comuns, que podem ou não derivar de responsabilidades legais formalmente prescritas e não dependem, necessariamente, do poder de polícia para que sejam aceitas e vençam resistências. Em outras palavras, governança é um fenômeno mais amplo do que governo; abrange instituições governamentais, mas implica também em mecanismos informais de caráter não-governamental, que fazem com que as pessoas e organizações dentro de sua área de atuação tenham uma conduta determinada, satisfaçam suas necessidades e respondam suas demandas [...] A governança é um sistema de ordenação que só fun- 
ciona se for aceito pela maioria (ou pelo menos pelos atores mais poderosos do seu universo), enquanto governos podem funcionar mesmo em face de ampla oposição à sua política.

A perspectiva liberal de Rosenau (2000) é bem negativa frente ao governo. Rosenau (2000) parece considerar melhor o acordo entre agentes com grande poder na sociedade, incluindo o poder econômico, do que o arranjo soberano de poder, mesmo quando fundado em um regime democrático. A ação de governo, para Rousenau (2000), remete à instituição estatal e governar significa dirigir a instituição do Estado. Para Foucault (2008b, 2010), governar é conduzir condutas dos indivíduos e dos processos coletivos disseminados na sociedade, incluindo a disciplina dos corpos e o controle. Sem dúvida, o direcionamento dessas condutas também existe dentro do Estado e conduz, também, as ações dos gestores e administradores públicos. Somente com base na existência da lei e da hierarquia não podemos extrair uma maior compreensão dos jogos de poder e dos usos de dispositivos que definem determinadas trajetórias e ações dos operadores das instituições estatais.

A proposta da governamentalidade abre espaço para compreender os dispositivos específicos de governo e o desenvolvimento de saberes que redundaram em estratégias e políticas de controle das populações. Também permite observar a relação dos dispositivos técnicos com a lei (aparato jurídico), com a norma (usos consolidados, costumes e ética cotidiana), com os gestores e com as pessoas em interação com o Estado. $\mathrm{O}$ termo governança poderia ser empregado se fosse entendido mais amplamente, no mesmo sentido que Foucault emprega a expressão governo. Todavia, aqui será utilizada a palavra governo para tratar da questão que Ben Wagner (2016, p. 5) tão bem estruturou: "[...] como são governados os algoritmos embutidos no software?". Acrescento à questão anterior, as seguintes perguntas: qual o nível de controle que os gestores públicos têm sobre os algoritmos que utilizam? Como deveria ser estruturada uma prática democrática de governo dos algoritmos?

\section{INVISIBILIDADE, NEUTRALIDADE E DIMENSÃO PÚBLICA}

Nem softwares, nem os algoritmos nele contidos são neutros. Eles geram efeitos e foram criados e desenvolvidos para determinadas finalidades. Apesar de serem imateriais e invisíveis, os algo- 
ritmos têm um ponto de partida e uma finalidade original que pode ter sido alterada pelos seus usuários ou pelo próprio algoritmo, caso tenha embutido em seu código rotinas de autocorreção e aprendizagem. Algoritmos são invenções, e, como toda invenção, guarda as intenções dos seus criadores. Isso é muito importante, pois os algoritmos não são desenvolvidos pelo setor público; em geral, nascem dentro de empresas e corporações que os vendem ao Estado. Para serem vendidos, são apresentados como maravilhas técnicas, como soluções que simplesmente fazem o que queremos, sem interferir em nossas práticas, em nossos gostos, em nossas opiniões e em nossa forma de classificar e ver. O algoritmo, como produto, para parecer mais eficaz deve parecer mais neutro, completamente adequado e submetido aos interesses de seus compradores.

Primeira grande questão: os algoritmos são invisíveis, complexos e escritos em linguagem matemática. Por ser invisíveis, para muitos, os algoritmos não são percebidos, na prática é como se não existissem. $\mathrm{O}$ grande problema é que sua invisibilidade e virtualidade geram efeitos reais e de grande relevância. Vamos a um recente exemplo. Em setembro de 2015, a Agência de Proteção Ambiental (EPA), dos Estados Unidos, descobriu que o software instalado na central eletrônica dos carros da Volkswagen possuía um algoritmo que conseguia identificar quando o veículo estivesse submetido à condição de teste, reduzindo naquele momento os poluentes emitidos pelo motor. A fraude só foi descoberta com o apoio de pesquisadores da Universidade de West Virginia. O Conselho de Emissões da Califórnia (CARB) e a EPA estimam que 482 mil veículos, fabricados entre 2009 e 2015, com motores diesel, violavam a legislação ambiental. (ESCÂNDALO..., 2015). Algoritmos não são visíveis, nem perceptíveis, mas são contundentes na execução de sua finalidade.

A segunda grande questão advém da força do positivismo que já era grande na sociedade industrial e cresceu na sociedade informacional. $\mathrm{O}$ positivismo foi transformado em senso comum e articulado pelo neoliberalismo como um dos sustentáculos de sua racionalidade. Isso fortalece o marketing das corporações que fornecem tecnologias para o Estado como meros produtos cujo sentido e uso é definido pelo comprador. A imaterialidade e invisibilidade dos softwares e algoritmos reforçam a prática discursiva de uma tecnicidade neutra de uma racionalidade naturalizada que implicam o tratamento não-político e não-crítico dos códigos no setor público. 
Um passo importante para recuperar a capacidade crítica diante dos algoritmos é tentar compreender sua dimensão pública e suas implicações políticas. O estudioso dos algoritmos, Tarleton Gillespie (2013, p. 168, tradução nossa), destacou seis dimensões dos "[...] algoritmos de relevância pública" que têm validade política. A primeira diz respeito aos padrões de inclusão utilizados pelos algoritmos. Eles definem claramente o que deve ou não ser incluído em suas operações. Também são projetados para antecipar a escolha dos usuários em diversos ciclos de antecipação. Uma das principais funções dos algoritmos é a avaliação de relevância, ou seja, ser capaz de obter quais informações são mais ou menos importantes para cada pessoa. Todas as operações algorítmicas portam a promessa da objetividade, acima de opiniões e pontos de vista. Em seu emaranhamento com a prática dos usuários, os algoritmos os alteram e são também alterados por sua dinâmica. Por fim, Gillespie observou que os algoritmos produzem públicos calculados, amostras que passam a reconfigurar a visão que possuem do seu próprio grupo.

\section{PERFORMATIVIDADE E TOMADA DE DECISÃO NO SETOR PÚBLICO}

Cada vez mais, os administradores e gestores de empresas privadas e instituições públicas delegam aos softwares uma série de tarefas e decisões. Em geral, os softwares possuem diversos algoritmos que foram criados para realizar diferentes cálculos, classificações e correlações, entre outras atividades mais complexas. Várias decisões, antes tomadas por pessoas, estão sendo substituídas por decisões adotadas por algoritmos. Na administração pública brasileira atual, o nível das soluções dadas por algoritmos ainda é considerado de um baixo grau de importância, mas sua relevância aumentará com o avanço do big data, da disseminação de sensores conectados às redes e com o crescimento das cidades digitais e inteligentes. Atualmente, muitas soluções já automatizadas estão substituindo esquemas operados por algoritmos mais complexos, como no caso dos municípios que passaram a utilizar os semáforos inteligentes. Outro exemplo pode ser encontrado na organização do atendimento público, os algoritmos passam a gerenciar a prioridade de recepção nas repartições públicas superando a simples ordem de chegada.

Algoritmos parecem envolver duas formas de automação relacio-
nadas, mas muito diferentes. Em primeiro lugar, eles automatizam
o processo de submeter dados à análise, realizando tarefas que se- 
riam impossíveis de executar manualmente. Mas os resultados dessas análises ajudam a automatizar um segundo e muito diferente conjunto de operações: a tomada de decisão. (BAROCAS; HOOD; ZIEWITZ, 2013, p. 5, tradução nossa).

Os riscos dessa automatização podem ser observados quando o grau de importância social das decisões aumenta. Nos últimos trinta anos, os modelos estatísticos e softwares têm penetrado na justiça penal norte-americana para apoiar os juízes e procuradores na avaliação do risco e na definição das penas dos criminosos. (CHRISTIN; ROSENBALT; BOYD, 2015). Em 2015, a Arnold Foundation lançou um novo instrumento, o Public Safety Assessment - Court (PSA), que se baseia em diversas variáveis relacionadas com a idade, moradia, histórico criminal, entre outras, para definir a pena, a fiança e a liberdade condicional dos réus. Segundo os pesquisadores Christin, Rosenblat e Boyd (2015), o PSA era usado por 21 jurisdições, incluindo três Estados inteiros (Arizona, Kentucky e New Jersey) e três cidades principais (Charlotte, Chicago, e Phoenix), em 2015. De acordo com a Fundação Arnold, a utilização do PSA tem reduzido as taxas de criminalidade e também a população carcerária nas jurisdições onde foi usado. Contudo, as definições algorítmicas também têm sido apontadas como reprodutoras e ampliadoras do racismo e seletividade do Judiciário norte-americano. (MAYBIN, 2016).

Embora possamos entender como o algoritmo funciona, os resultados do algoritmo podem não ser previsíveis. Podemos entender como as redes neurais e o algoritmo de autoaprendizagem funcionam, mas eles podem gerar resultados que não podem ser previstos com antecedência. Isso complica a responsabilidade ex ante em que o algoritmo e seus projetistas são responsáveis pelas decisões. (JANSSEN; KUK, 2016, p. 374, tradução nossa).

É necessário discutir as implicações das decisões automatizadas efetuadas por algoritmos que possuem a capacidade de aprendizagem ou de revisão a partir de informações obtidas após sua ação anterior. O algoritmo utilizado pelo motor de busca do Google é desse tipo. A cada busca que fazemos, o algoritmo aprende com os temas que mais nos interessam, com as escolhas de links que fazemos e com outros elementos que conformam as nossas opções preferenciais. Assim, o algoritmo recolhe dados sobre nossas ações, nossas preferências e definem nosso perfil. Eli Pariser (2012) chamou esse processo de personalização, de classificação e inserção de 
nossas identidades em grupos específicos de filter bubble. Nem os desenvolvedores que criaram o algoritmo conseguem saber como ele agirá depois de um tempo de funcionamento, pois ele aprendeu com os dados coletados, enfim as decisões do algoritmo possuem vínculo com sua origem, mas sua autonomia decisória é grande, difícil de estimar.

Esses algoritmos são dispositivos performativos. Em linguística, um enunciado é performativo quando ocorre simultaneamente a ação que ele apresenta, ou seja, há uma coincidência entre a palavra e o ato. "A performatividade é uma perspectiva particular sobre a natureza da interação, que é o resultado lógico de uma posição ontológica do tornar-se (também conhecida como filosofia do processo) em oposição a uma ontologia do ser." (INTRONA, 2013, p. 2 , tradução nossa). Portanto, o controle de dispositivos que se alteram constantemente traz uma série de novos desafios para quem os utiliza. Os problemas podem ser maiores quando tratamos do uso de algoritmos performativos nas decisões do setor público, onde a responsabilidade pelos atos da gestão, a transparência e a estabilidade jurídica é fundamental.

Machine Learning ou Aprendizagem de Máquina é o campo de estudo que se concentra em algoritmos de indução e em outros algoritmos que são definidos por sua capacidade de aprender (KOHARI; PROVOST, 1998). Esses algoritmos que aprendem com a experiência já estão sendo empregados por auditores fiscais para a deteç̧ão de fraudes, mas poderão ser utilizados para administrar o trânsito de uma cidade, para organizar o sistema de matrículas e as turmas em uma grande universidade ou em um sistema regional de ensino, entre outros exemplos. Todavia, esses algoritmos podem engendrar procedimentos não pretendidos, mas criados por indução. Segundo o professor do MIT Media Lab, Kevin Slavin, em 2011, o algoritmo que regula os preços na Amazon entrou em um processo de concorrência desenfreada entre os títulos da própria loja virtual. Um dos livros de Biologia, The Making of a Fly, chegou a custar US\$ 23,6 milhões. (ESPECIALISTA..., 2011). Erros similares podem ser produzidos por algoritmos preditivos, ou seja, que realizam prognósticos a partir do acompanhamento de perfis e de elementos que compõem sua área de decisão.

Uma das principais questões que aparecem para a gestão pública em torno de algoritmos performativos e preditivos é a seguinte: 
como o gestor pode governar um algoritmo que se altera constantemente? Como é possível torná-lo transparente para os gestores e para a sociedade que é governada por ele? Esses questionamentos têm uma dimensão técnica, mas são políticos, pois dizem respeito a decisões sobre a vida das cidadãs e cidadãos. Com base no potencial performativo e preditivo dos algoritmos é possível adotar no setor público alguns passos importantes:

1 - Softwares e algoritmos devem ter o código-fonte aberto. Essa decisão esbarra nos modelos de negócios de empresas fornecedoras de tecnologia para o Estado, que se baseiam em licenças de propriedade intelectual restritivas.

2 - Código-aberto não é suficiente para acompanhar a atuação dos algoritmos performativos. Por isso, é necessário adotar procedimentos de auditoria, avaliação frequente e correção de rumos e de decisões adotadas.

3 - Delimitadores de decisão devem ser incorporados nos algoritmos, ou seja, o gestor público deve impor fronteiras decisórias para os algoritmos, o que evitará equívocos previsíveis e considerados inaceitáveis.

4 - Incorporar nos projetos de desenvolvimento de softwares e algoritmos os procedimentos que assegurem a privacidade no armazenamento, processamento e uso de dados pessoais, indispensáveis para o serviço público. Isso implica necessariamente a adoção de criptografia e níveis de acesso para proteger os dados dos cidadãos.

5 - Dados pessoais que não são indispensáveis não devem ser coletados. Isso evita diversas dificuldades e custos em sua proteção.

6 - Toda gestão de dados deve possuir documentos descrevendo sua guarda e utilização. Essas declarações de política de privacidade e de gestão algorítmica devem ser transparentes, de fácil acesso e possuir mecanismos claros para garantir o seu cumprimento.

7 - Algoritmos de dimensão pública não podem ser criados e desenvolvidos sem a participação dos gestores e administradores públicos. Não são neutros, nem apenas técnicos, portanto, não devem ser comprados como se compram mercadorias padronizadas. Não é a gestão pública que 
deve se adequar às soluções disponíveis no mercado, mas as soluções adquiridas devem ser adequadas aos interesses e peculiaridades do setor público.

Esses procedimentos não evitam as possíveis distorções e implicações negativas que os algoritmos podem gerar na organização e nas decisões e práticas dos serviços públicos. Lucas Introna (2013) alerta que a lógica algorítmica é reducionista. Os problemas são reduzidos para que sejam expressos algoritmicamente e são formatados conforme os conhecimentos técnicos disponíveis pelos programadores. Além disso, em geral, os problemas são adequados às soluções disponíveis e aos produtos vendidos pelas corporações. Este reducionismo pode ter consequências performativas significativas. (INTRONA, 2013).

Donald MacKenzie afirmou que os algoritmos não expressam simplesmente o mundo, as intenções dos programadores, as funções e os processos que automatizam. Os algoritmos não modelam o mundo, mas executam performativamente ações sobre uma realidade que vai produzindo diferentes entidades à medida que agem. $\mathrm{Ob}-$ servando o mercado financeiro, Mackenzie (2008) nos mostra que os modelos matemáticos e os sistemas de negociação financeira não apenas automatizam o cálculo do valor. Essa modelagem e dinâmica algorítmica cria novas práticas e gera novos comportamentos dos gestores de fundos, dos analistas e dos investidores que incorporam a agência de tais modelos na realização de suas escolhas. (MACKENZIE, 2008).

Neste sentido, o uso crescente de algoritmos na gestão e nos serviços públicos não pode ser visto como simplesmente uma inovação ou uma mera modernização. Deve ser compreendido no contexto que Lucas Introna (2013) chamou da performatividade dos algoritmos, de governo dos algoritmos que governam as áreas do setor público em que atuam. Introna (2013) propõe que sejamos capazes de localizar, compreender a noção da atribuição de agência dada aos algoritmos. Precisamos assumir que os algoritmos possuem consequências normativas e performativas relacionadas ao poder destinado ao seu projeto.

5 CONCLUSÃO: controle e governo dos algoritmos

Governar implica utilizar dispositivos e tecnologias de controle. Para o exercício do governo das populações, desde o século 
XVIII, têm sido utilizados instrumentos estatísticos, as ciências sociais e outras tecnologias biopolíticas. (FOUCAULT, 2010). Atualmente, as tecnologias da informação trazem vantagens irrecusáveis para a gestão dos governos e instituições do Estado. A aplicação generalizada do big data na gestão pública tenderá a estruturar um campo bem maior para o uso de algoritmos, talvez na mesma direção em que eles são utilizados no mercado financeiro. Algoritmos de alta frequência vão conduzindo os investimentos e reformatando a dinâmica dos mercados de alto risco. (GILES, 2012).

Algoritmos são desenvolvidos fora do Estado. Talvez seja preciso repensar essa prática aclamada e voltada às empresas. Foucault (2008a, p.164-165) nos mostrou que o liberalismo buscou estabelecer formas não estatais de governamentalidade dos viventes: "[...] é necessário governar para o mercado, em vez de governar por causa do mercado". Já para o neoliberalismo, não é o mercado, mas a concorrência que deve ser o princípio regulador de tudo. (FOUCAULT, 2008a). E quem deve representar e se proliferar nesse mundo concorrencial são as empresas. Elas devem ser a medida da verdade e da verificação se algo está sendo executado corretamente ou não. "É essa multiplicação da forma 'empresa' no interior do corpo social que constitui, a meu ver, o escopo da política neoliberal." (FOUCAULT, 2008a, p. 203, grifo do autor).

As sociedades democráticas precisam assumir que o cenário atual é tecnopolítico. Tal como o velho tecnocrata que acreditava na supremacia do seu saber técnico, algumas correntes dos novos gestores públicos, encantados com as promessas neoliberais e seu discurso de inovação, acreditam que as empresas criam softwares e algoritmos que funcionam maravilhosamente bem, pois são produtos que devem ser adquiridos pelo melhor preço, dada a uma variedade de ofertas concorrentes. Abrem mão de criar e desenvolver os dispositivos tecnológicos de governo, como se estes fossem apolíticos. Acabam contribuindo para fazer da sociedade um agregado conduzido pelas corporações privadas. Nesse contexto, os algoritmos são actantes (LATOUR, 1994) cada vez mais sem transparência e seus efeitos podem representar perigos para as democracias, para a deliberação democrática e para as gestões inclusivas.

A alternativa ao positivismo e às perspectivas da neutralidade algorítmica pode estar na formação de redes de compartilhamento de soluções algorítmicas, na compreensão de que a construção de 
softwares para o setor público é um processo, e não um produto acabado a ser adquirido no mercado. Também pode estar na criação de coletivos de gestão algorítmica e de tecnologias da informação. Uma das tarefas iniciais desses coletivos poderia ser a realização de um mapeamento dos algoritmos, das decisões que já são e que poderiam ser automatizadas, bem como a formulação de políticas de uso dos dados e de proteção da privacidade dos cidadãos. Sem dúvida, o setor público para atuar tecnopoliticamente deverá se aproximar mais das universidades e dos coletivos de cultura tecnológica, dos hackers e dos makers.

\section{REFERÊNCIAS}

BAROCAS, S.; HOOD, S.; ZIEWITZ, M. Governing algorithms: a provocation piece. In: GOVERNING ALGORITHMS: a conference on computation, automation, and control, 2013, New York. Anais. New York, 2013. Disponível:<https://papers.ssrn.com/sol3/papers. cfm?abstract_id=2245322>. Acesso em: 5 out. 2016.

CASTELLS, M. A era da informação: economia, sociedade e cultura. São Paulo: Paz e Terra, 1999.

CHRISTIN, A.; ROSENBLAT, A.; BOYD, D. Courts and Predictive Algorithms. In: DATA AND CIVIL RIGHT: Criminal Justice and Civil Rights Primer, 2015, Washington, DC. Anais... Washington, DC: Data \&Society, 2015.

ESCÂNDALO da Volkswagen: veja como a fraude foi descoberta. G1, São Paulo, 2015. Auto Esporte. Disponível:<http://g1.globo.com/ carros/noticia/2015/09/escandalo-da-volkswagen-veja-o-passo-passodo-caso.html>. Acesso: 10 jan. 2017.

ESPECIALISTA alerta para ameaça dos algoritmos. IG, São Paulo, ago. 2011. Tecnologia. Disponível em: $<$ http://tecnologia.ig.com.br/ especialista-alerta-para-ameaca-dos-algoritmos/n1597173189284. html>. Acesso em: 10 jan. 2017.

FOUCAULT, M. Em defesa da sociedade: curso no Collège de France (1975-1976). $2^{\mathrm{a}}$ ed. São Paulo: Editora WMF Martins Fontes, 2010.

. Nascimento da biopolítica: curso dado no College de France (1978-1979). São Paulo: Martins Fontes, 2008a.

. O sujeito e o poder. In: DREYFUS, H. L.; RABINOW,

P. Michel Foucault - Uma Trajetória Filosófica: para além do 
estruturalismo e da hermenêutica. Rio de Janeiro: Forense Universitária, 1995. p. 251-269.

. Seguranca, território, população: curso dado no College de France (1977-1978). São Paulo: Martins Fontes, 2008 b.

GILES, J. Stock trading 'fractures' may warn of next crash. New Scientist, [S. 1.], feb. 2012. Disponível em: $<$ https://www.newscientist. com/article/dn21455-stock-trading-fractures-may-warn-of-nextcrash/>. Acesso em: 10 jan. $/ 2017$.

GILLESPIE, T. The Relevance of Algorithms. In: GILLESPIE, T.; BOCZKOWSKI, P. J.; FOOT, K. A. Media technologies: essays on communication, materiality, and society. Cambridge, MA: MIT Press, 2014.

GOFFEY, A. Algorithm. In: FULLER, M. (Ed.). Software studies: a lexicon. Cambridge, MA: MIT Press, 2008. p. 15-20.

HOWARD, P. N. Pax technica: how the Internet of things may set us free or lock us up. New Haven: Yale University Press, 2015.

INTRONA, L. D. Algorithms, performativity and governability (early draft). In: GOVERNING ALGORITHMS: a conference on computation, automation, and control, 2013, New York. Anais. New York, 2013. Disponível:<http://governingalgorithms.org/wp-content/ uploads/2013/05/3-paper-introna.pdf>. Acesso: 15 dez. 2016.

JANSSEN, M.; KUK, G. The challenges and limits of big data algorithms in technocratic governance. Government Information Quarterly, [S. 1.], v. 33, n. 3, p. 371-377, 2016.

KOHARI, R.; PROVOST, F. Glossary of Terms: special Issue on Applications of Machine Learning and the Knowledge Discovery Process. Machine Laerning, Boston, v. 30, n. 2-3, p. 271-274, feb./ mar. 1998. Disponível:<http://ai.stanford.edu/ ronnyk/glossary.html>. Acesso em: 10 jan. 2017.

KOWALSKI, R. Algorithm= logic + control. Communications of the ACM, New York, v. 22, n. 7, p. 424-436, 1979.

LATOUR, B. Jamais fomos modernos. Rio de Janeiro: Editora 34, 1994.

LEVI, L. Governo. In: BOBBIO, N. et al. (Orgs.). Dicionário de Política. 2. ed. Brasília, DF: Ed. UNB, 1986.

MACHLUP, F. The production and distribution of knowledge in the United States. Princeton: Princeton University Press, 1962. 
MACKENZIE, D. An engine, not a camera: how financial models shape markets. Cambridge, MA; London: Mit Press, 2008.

MANOVICH, L. Software takes command. New York: A\&C Black, 2013.

MAYBIN, S. Sistema de algoritmo que determina pena de condenados cria polêmica nos EUA. BBC News, São Paulo, out. 2016. Disponível em: $<$ http://www.bbc.com/portuguese/brasil-37677421>. Acesso: 15 dez. 2016.

PARISER, E. O filtro invisível: o que a internet está escondendo de você. São Paulo: Zahar, 2012.

ROSENAU, J. N. Governança, ordem e transformação na política mundial. In: ROSENAU, J; CZEMPIEL, O. Governança sem Governo. Brasília, DF: Ed. UnB, 2000. p. 11-46.

WAGNER, B. Algorithmic regulation and the global default: shifting norms in Internet technology. Etikk i Praksis: Nordic Journal of Applied Ethics, Norway, v. 10, n. 1, p. 5-13, 2016.

WEBER, M. Ciência e política: duas vocações. São Paulo: Editora Cultrix, 2004. 
